\title{
Isobavachalcone, a Chalcone Constituent of Angelica keiskei, Induces Apoptosis in Neuroblastoma
}

\author{
Reiko Nishimura, ${ }^{a}$ Keiichi Tabata, ${ }^{a}$ Motoki Arakawa, ${ }^{b}$ Yoshihisa Ito, ${ }^{b}$ Yumiko Kimura, ${ }^{c}$ \\ Toshihiro Akihisa, ${ }^{d}$ Hisashi NAgaI, ${ }^{d}$ Atsuko SAKuma, ${ }^{d}$ Hideki Kohno, ${ }^{e}$ and Takashi Suzuki ${ }^{*}, a, f$ \\ ${ }^{a}$ Research Unit of Clinical Medicine, College of Pharmacy, Nihon University; ${ }^{b}$ Research Unit of Pharmacology, College \\ of Pharmacy, Nihon University; ${ }^{c}$ Research Unit of Analytical Chemistry of Pharmaceuticals, College of Pharmacy, Nihon \\ University; 7-7-1 Narashinodai, Funabashi-shi, Chiba 274-8555, Japan: ${ }^{d}$ Department of Materials and Applied \\ Chemistry, College of Science and Technology, Nihon University; 1-8 Kanda Surugadai, Chiyoda-ku, Tokyo 101-8301, \\ Japan: ${ }^{e}$ Department of Applied Molecular Chemistry College of Industrial Technology, Nihon University; 1-2-1 Izumicho, \\ Narashino-shi, Chiba 275-8575, Japan: and ${ }^{f}$ Department of Pediatrics and Child Health, Nihon University School of \\ Medicine; 30-1 Oyaguchikami-cho, Itabashi-ku, Tokyo 173-0032, Japan.
}

Received March 15, 2007; accepted July 25, 2007; published online July 26, 2007

Six chalcones from Angelica keiskei KoIDzumi (Ashitaba in Japanese) and two chalcones from Humulus lupulus L. (hop) were examined for their cytotoxicity in two human neuroblastoma cell lines (IMR-32 and NB39) and normal cells (primary culture of rat cerebellar granule cells) by [3-(4,5)-dimethyl-2-thiazolyl]-2,5diphenyl-2H-tetrazolium bromide (MTT) assay. All chalcones exhibited cytotoxicity against neuroblastoma cells, and two of them (isobavachalcone and xanthoangelol $\mathrm{H}$ ) had no effect on normal cells even at high concentration $\left(10^{-4} \mathrm{M}\right)$ exposure. Typical morphologic features of apoptosis, including cell shrinkage, chromatin condensation, nuclear fragmentation and formation of apoptotic bodies, were observed in isobavachalcone-treated cells by Hoechst 33342 staining. Western blot analysis showed that isobavachalcone significantly reduced pro-caspase-3 and pro-caspase-9, and subsequently increased the level of cleaved caspase-3 and cleaved caspase-9 in both neuroblastoma cell lines. Moreover, Bax was markedly induced by isobavachalcone application. These results suggest that isobavachalcone induces apoptotic cell death in neuroblastoma via the mitochondrial pathway and has no cytotoxicity against normal cells. Therefore, isobavachalcone may be applicable as an efficacious and safe drug for the treatment of neuroblastoma.

Key words neuroblastoma; apoptosis; isobavachalcone

Neuroblastoma, the most common solid extracranial neoplasm in children, originates from embryonic neural crest cells that usually form the sympathetic ganglia and adrenal medulla. ${ }^{1)}$ Neuroblastoma accounts for $15 \%$ of pediatric tumors and has a poor prognosis in children after 1 year of age. ${ }^{2)}$ Despite advanced multimodal therapies, including radiotherapy, surgery, and a variety of chemotherapy regimens, stage IV neuroblastoma patients have an extremely poor prognosis. Approximately $50 \%$ of all patients present with advanced stage IV, by which time most of them show metastatic dissemination. ${ }^{3)}$ The 5-year survival rate of patients with stage IV is as low as $20-25 \%{ }^{3)}$ Therefore, novel therapeutic strategies are urgently needed to improve the prognosis of these patients. On the other hand, some types of neuroblastoma, especially in infants under 1 year of age, are known to regress spontaneously or mature even if widespread metastases to bone marrow, skin and/or liver (special stage: IV-S) are present.

Apoptotic cell death is a key mechanism for normal cellular homeostasis. Intact apoptotic mechanisms are pivotal for embryonic development, tissue remodeling, immune regulation, and tumor regression. Genetic aberrations disrupting programmed cell death often underpin tumorigenesis and drug resistance. The activation mechanisms of the apoptotic program could increase the effects of therapy for tumors including neuroblastoma. ${ }^{4)}$ It is known that apoptosis is induced mainly by triggering of the mitochondria (intrinsic pathway) or death receptors (extrinsic pathway), leading to the activation of caspases. ${ }^{5}$ It has been suggested previously that apoptosis participates in spontaneous regression in stage

\section{IV-S neuroblastoma. ${ }^{6}$}

Chemotherapy for the treatment of cancer is associated with various side effects such as nausea, vomiting, alopecia, constipation, bone marrow suppression, and infectious diseases. Ideally, chemotherapeutic drugs should specifically target only cancer cells. In practice, however, the use of chemotherapy is marred by various factors including systemic toxicity due to a lack of specificity, rapid drug metabolism, and intrinsic or acquired drug resistance. ${ }^{7)}$

Angelica keiskei KoIDzumI (Japanese common name "Ashitaba") is a hardy perennial herb growing mainly along the Pacific coast of Japan, and has been used traditionally in Japan as a diuretic, laxative, analeptic and galactagogue. Previously, it has been reported that $A$. keiskei extract produces elevation of the serum HDL level and a reduction of liver triglyceride levels in hypertensive rats. $\left.{ }^{8}\right)$ Some chalcones isolated from $A$. keiskei inhibit phenylephrine-induced vasoconstriction in vivo ${ }^{9}$ and regulate nuclear factor (NF)- $\kappa \mathrm{B}$ activation. ${ }^{10)}$ Moreover, some chalcones isolated from it reportedly have inhibitory effects against tumor promoter activity, ${ }^{11-13)}$ antitumor and antimetastatic activities ${ }^{14,15)}$ Humulus lupulus (commonly known as "hop cones" or "hops") is cultivated in the temperate zones of the world. It is a very important component of beer, which is an integral part of the diet in many cultures. Hop cones are used therapeutically as a mild sedative, and are listed in the European Pharmacopoeia. Some constituents of hop reportedly have some antitumor activities such as prevention of carcinogen-induced preneoplastic lesions, ${ }^{16)}$ antiangiogenic activity, ${ }^{17)}$ antiproliferative and cytotoxic activity ${ }^{18)}$ and anti-invasive activity. ${ }^{19)}$ Furthermore, it 
has been reported that chalcones isolated from hop induce apoptosis against various cancer cells. ${ }^{20,21)}$ However, there have been few reports on the effects of chalcones on human neuroblastoma.

In the present study, we aimed to identify agents that induce apoptosis in neuroblastoma cells without toxic effects on normal cells. The cytotoxic effects of six chalcones purified from $A$. keiskei and two chalcones from $H$. lupulus were examined against two human neuroblastoma cell lines (IMR32 and NB-39). We also investigated whether chalcones act selectively on tumor cells by comparison with normal cells (rat cerebellar granule cells). Furthermore, we studied the apoptosis-inducing activity of a constituent that was found to have selective cytotoxicity against neuroblastoma cells.

\section{MATERIALS AND METHODS}

Materials [3-(4,5)-dimethyl-2-thiazolyl]-2,5-diphenyl$2 \mathrm{H}$-tetrazolium bromide (MTT), dimethyl sulfoxide (DMSO), basal medium eagle (BME), Hoechst 33342, protease inhibitor cocktail I, phosphatase inhibitor cocktail II, rabbit polyclonal anti-caspase-3 antibody, mouse monoclonal anti-Bcl-2 antibody (Bcl-2-100), mouse monoclonal anti-Bax antibody (2D2), mouse monoclonal anti- $\beta$-tubulin (TUB2.1) antibody, anti-rabbit-IgG antibody conjugated with HRP, and anti-mouse-IgG antibody conjugated with HRP were purchased from Sigma Chemical Co. (St. Louis, MO, U.S.A.). FBS (for BME medium) was purchased from Thermo Trace (Melbourne, Australia). Gentamicin, Ara-C, and BSA were purchased from Wako Pure Chemical Industries Ltd. (Osaka, Japan). RPMI-1640 medium, phenol red-free RPMI-1640 medium, fetal bovine serum (FBS) (for RPMI 1640 medium), and penicillin-streptomycin were purchased from Invitrogen Co. (Carlsbad, CA, U.S.A.). Rabbit polyclonal cleaved caspase-3 (Asp175) antibody, mouse monoclonal caspase-8 (1C12) antibody and rabbit polyclonal caspase-9 antibody were purchased from Cell Signaling (Beverley, MA, U.S.A.). An enhanced chemiluminescence (ECL) Western blotting detection system and polyvinylidene difluoride (PVDF) membranes were purchased from GE Healthcare (Buckinghamshire, England).

Chalcones We obtained $22.3 \mathrm{~g}$ of dried yellow sap extract from stems of $A$. keiskei. The extract yielded six chalcones: $2286.6 \mathrm{mg}$ xanthoangelol (1) (10.3\% of the dried yellow sap), $545.2 \mathrm{mg}$ xanthoangelol F (2) (2.44\%), $2093.1 \mathrm{mg}$ 4-hydroxyderricin (3) (9.39\%), $29.8 \mathrm{mg}$ isobavachalcone (4) $(0.134 \%), 1.1 \mathrm{mg}$ xanthoangelol $\mathrm{H}$ (5) $(0.0049 \%)$, and $3.4 \mathrm{mg}$ xanthoangelol I (6) $(0.0152 \%){ }^{11)}$ From $H$. lupulus, we obtained $287 \mathrm{~g}$ of extract, which yielded two chalcones: $43.5 \mathrm{mg}$ xanthohumol (7) $(0.0152 \%$ of the extract), and $2.9 \mathrm{mg} 4-O$-methylxanthohumol (8) $(0.0010 \%)$. These chemical structures are shown in Fig. 1. All chalcones were dissolved in DMSO (DMSO final concentration $0.2 \%$ ).

Cell Cultures All efforts were made to minimize the number of animals used and their suffering. All experiments with animals complied with the Ethical Guidelines for Animal Experiments of Nihon University. Cultures rich in cerebellar granule neurons were prepared from 7- to 8-d-old Wistar rats as reported previously. ${ }^{22,23)}$ Cells were plated at a density of $3.5 \times 10^{5}$ cells $/ \mathrm{cm}^{2}$ in BME supplemented with $25 \mathrm{~mm}$ potassium chloride, $10 \% \mathrm{FBS}$ and $20 \mathrm{mg} / \mathrm{ml}$ gentamicin on
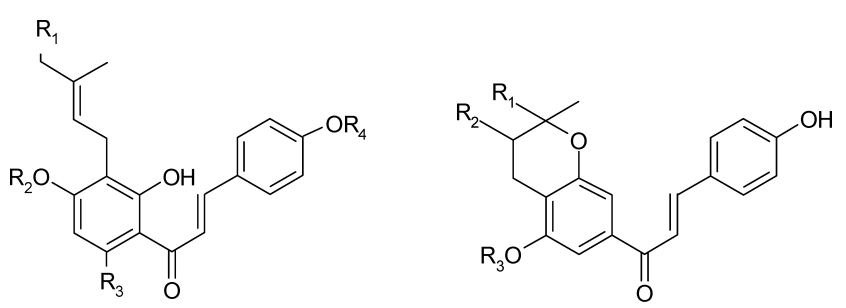

$\begin{array}{lllll} & \mathbf{R}_{1} & \mathbf{R}_{2} & \mathbf{R}_{3} & \mathbf{R}_{4} \\ (1) & - & -H & -H & -H \\ (2) & - & -C_{3} & -H & -H \\ (3) & -H & -\mathrm{CH}_{3} & -\mathrm{H} & -\mathrm{H} \\ (4) & -\mathrm{H} & -\mathrm{H} & -\mathrm{H} & -\mathrm{H} \\ (7) & -\mathrm{H} & -\mathrm{H} & -\mathrm{OCH}_{3} & -\mathrm{H} \\ (8) & -\mathrm{H} & -\mathrm{H} & -\mathrm{OCH}_{3} & -\mathrm{CH}_{3}\end{array}$

$\begin{array}{llll} & \mathbf{R}_{1} & \mathbf{R}_{2} & \mathbf{R}_{3} \\ \text { (5) } & -\mathrm{H} & -\mathrm{OH} & -\mathrm{CH}_{3} \\ \text { (6) } & - & -\mathrm{H} & -\mathrm{H}\end{array}$

Fig. 1. Chemical Structures of Xanthoangelol (1), Xanthoangelol F (2), 4Hydroxyderricin (3), Isobavachalcone (4), Xanthoangelol H (5) and Xanthoangelol I (6) Purified from A. keiskei, and Xanthohumol (7) and 4-OMethylxanthohumol (8) Purified from $H$. lupulus

24-well cell culture plates (Corning, NY, U.S.A.). The cells were maintained at $37^{\circ} \mathrm{C} / 5 \% \mathrm{CO}_{2}$ in a humid environment and were stimulated on day 7 or 8 of culture. IMR-32 and NB-39 cells were maintained in RPMI-1640 medium supplemented with $100 \mathrm{U} / \mathrm{ml}$ penicillin, $100 \mathrm{mg} / \mathrm{ml}$ streptomycin and $10 \%$ FBS in a plastic flask (Corning, NY, U.S.A.). The cells were maintained at $37^{\circ} \mathrm{C} / 5 \% \mathrm{CO}_{2}$ in a humid environment.

MTT Reduction Assay The method is based on the ability of living cells to reduce MTT tetrazolium salt into MTT formazan by the mitochondrial enzyme succinate dehydrogenase. IMR-32 and NB-39 cells $\left(5 \times 10^{4}\right.$ cells/well $)$ were spread onto 24-well cell culture plates with medium and maintained for $24 \mathrm{~h}$. Normal cells were prepared as described above. Then chalcones (final concentration $1 \times 10^{-4}, 1 \times 10^{-5}$, $1 \times 10^{-6} \mathrm{M}$ ), corresponding cell culture medium (normal control) and DMSO (vehicle control) were applied for $48 \mathrm{~h}$. As reported previously, ${ }^{24-26)}$ the cells were incubated with MTT solution $(1.5 \mathrm{mg} / \mathrm{ml})$ for $4 \mathrm{~h}$ at $37^{\circ} \mathrm{C} / 5 \% \mathrm{CO}_{2}$. The reaction was stopped by addition of solubilization solution (50\% dimethylformamide, 20\% sodium dodecyl sulfate (SDS), $\mathrm{pH}$ 4.8) and left overnight to dissolve completely. The amount of MTT formazan product was determined by measuring absorbance at a test wavelength of $570 \mathrm{~nm}$ (peak) and $655 \mathrm{~nm}$ (bottom). The $50 \%$ inhibitory concentration $\left(\mathrm{IC}_{50}\right)$ was the concentration that caused a $50 \%$ decrease in the absorbance of drug-treated cells compared to the vehicle control.

Hoechst 33342 Staining Apoptotic nuclear morphology was observed by staining with Hoechst 33342. IMR-32 and NB-39 cells $\left(2 \times 10^{5}\right.$ cells/well $)$ were spread onto 6-well cell culture plates (Corning, NY, U.S.A.) with phenol redfree RPMI 1640 medium and incubated at $37^{\circ} \mathrm{C} / 5 \% \mathrm{CO}_{2}$ for $24 \mathrm{~h}$. Then, isobavachalcone (4) (final concentration $1 \times 10^{-4}-1 \times 10^{-6} \mathrm{M}$ ) was added and incubated for $4,8,24$ or $48 \mathrm{~h}$. Hoechst 33342 solution (final concentration $0.002 \%$ of medium) was added to the wells at $30 \mathrm{~min}$ before the end of exposure. After drug application, the cells were observed using a fluorescence microscope (BH2-RFL-T3, OLYMPUS, Tokyo, Japan).

Western Blot Analysis IMR-32 and NB-39 cells $\left(5 \times 10^{6}\right.$ cells/well $)$ were spread onto $60-\mathrm{mm}$ cell culture dishes (Corning, NY, U.S.A.) with RPMI 1640 medium and 
incubated at $37^{\circ} \mathrm{C} / 5 \% \mathrm{CO}_{2}$ for $24 \mathrm{~h}$. Then, isobavachalcone (4) (final concentration $1 \times 10^{-4}-1 \times 10^{-6} \mathrm{M}$ ) was added and incubated for $1,2,4,8,24$ or $48 \mathrm{~h}$. Cells were collected and lysed with lysis buffer $(20 \mathrm{~mm}$ Tris- $\mathrm{HCl} \mathrm{pH} 8.0,137 \mathrm{~mm}$ $\mathrm{NaCl}, 1 \%$ Nonidet P-40, 10\% glycerol, $1 \mathrm{~mm}$ phenylmethylsulfonylfluoride, protease inhibitor cocktail I $(1: 200)$, phosphatase inhibitor cocktail II $(1: 100)$, and $1 \mathrm{~mm}$ dithiothreitol). Protein concentration was determined using the Bradford method. ${ }^{27)}$ Cell lysates containing $20 \mu \mathrm{g}$ of total protein were loaded onto $15 \%$ SDS-polyacrylamide gels with Tris/glycine running buffer and transferred to PVDF membranes. Each membrane was blocked with blocking buffer (5\% skim milk in TTBS: $137 \mathrm{~mm} \mathrm{NaCl}, 0.1 \%$ Tween 20 and $20 \mathrm{~mm}$ Tris- $\mathrm{HCl}, \mathrm{pH}$ 7.6) for $1 \mathrm{~h}$ at room temperature and incubated with the primary antibody (anti-caspase-3 1:3000, anti-cleaved caspase-3 $1: 1000$, anti-caspase-9 $1: 1000$, anticaspase- $81: 500$, anti-Bax $1: 1000$, anti-Bcl-2 $1: 1000$ and anti- $\beta$-tubulin $1: 500$ diluted in TTBS containing $5 \%$ bovine serum albumin (BSA)) at $4{ }^{\circ} \mathrm{C}$ overnight. After washing with TTBS, the membrane was incubated with a secondary antibody conjugated with HRP $(1: 10000$, diluted in 5\% skim milk) at room temperature for $1 \mathrm{~h}$, and the signal was detected using an ECL Western blotting detection system. The density of the band was analyzed by NIH Image-J software.

Statistical Analysis The data are given as the mean \pm S.E.M. $(n=3)$. Significance testing was performed using one-way analysis of variance (ANOVA) followed by Bonferroni's correction.

\section{RESULTS}

Assessment of Chalcone Cytotoxicity The cytotoxic activities of chalcones against the two neuroblastoma cell lines (IMR-32 and NB-39) and cerebellar granule cells are shown in Table 1. We used cerebellar granule cells as normal cells because neuroblastoma is a disorder of neuronal cells. All chalcones exhibited potent cytotoxic activities with $\mathrm{IC}_{50}$ values of $1.80-20.0 \mu \mathrm{M}$ against both neuroblastoma cell lines. As a positive control, cisplatin-treated cells displayed cytotoxic activity with $\mathrm{IC}_{50}$ values of $64.0 \mu \mathrm{M}$ against IMR32 and $8.95 \mu \mathrm{M}$ against NB-39. In the experiment using normal cells, six chalcones $(\mathbf{1}, \mathbf{2}, \mathbf{3}, \mathbf{6}, \mathbf{7}, \mathbf{8})$ gave similar results to those obtained with neuroblastoma cells, with $\mathrm{IC}_{50}$ values of $10.5-26.5 \mu \mathrm{M}$. However, two chalcones, isobavachalcone

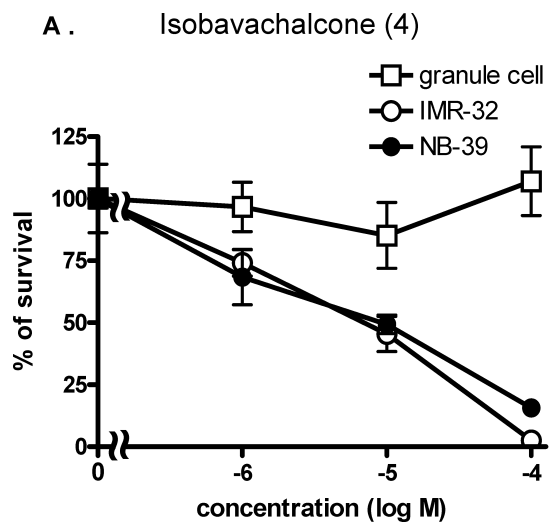

(4) and xanthoangelol H (5), had no effect on normal cells, with $\mathrm{IC}_{50}$ values of $>100 \mu \mathrm{M}$ (Table 1, Fig. 2). As the yield of xanthoangelol $\mathrm{H} \mathrm{(5)}$ isolated from the stem of $A$. keiskei was too low for use in the following experiment, we examined the mechanism of the neuroblastoma cytotoxicity of isobavachalcone in more detail.

Effect of Isobavachalcone on Cell Morphology The nuclear morphological changes were observed by Hoechst 33342 staining. In the control group, the nuclei of both types of neuroblastoma cells were round and homogeneously stained. Cells treated with isobavachalcone (4) $\left(1 \times 10^{-4} \mathrm{M}\right)$ showed typical morphologic features of apoptosis, such as cell shrinkage, chromatin condensation and fragmented fluorescent nuclei, which increased with application time $\left(1-48 \mathrm{~h}, 1 \times 10^{-4} \mathrm{M}\right)$ and concentration $\left(24 \mathrm{~h}, 1 \times 10^{-4}\right.$ $1 \times 10^{-6} \mathrm{M}$ ) in both IMR-32 and NB-39 (Fig. 3). In addition, cells treated with isobavachalcone (4) were shown to have apoptotic bodies by phase-contrast microscopy.

Effect of Isobavachalcone on Apoptosis-Related Proteins Caspase and $\mathrm{Bcl}$ family proteins such as Bcl-2 and Bax are believed to mediate the apoptotic pathway. To clarify the mechanism of isobavachalcone (4)-induced apoptotic cell death, we examined the contribution of caspase and Bcl family proteins using Western blot analysis.

The bands of pro-caspase-3 $(32 \mathrm{kDa})$ were slightly de-

Table 1. $\mathrm{IC}_{50}$ Values $(\mu \mathrm{M})$ of Chalcones against Neuroblastoma Cell Lines and Cerebellar Granule Cells

\begin{tabular}{|c|c|c|c|}
\hline \multirow{3}{*}{ Compounds } & \multicolumn{3}{|c|}{$\begin{array}{l}\text { Cytotoxicity } \\
\mathrm{IC}_{50}(\mu \mathrm{M})\end{array}$} \\
\hline & \multicolumn{2}{|c|}{ Neuroblastoma cells } & \multirow{2}{*}{$\begin{array}{c}\text { Normal cells } \\
\text { Cerebellar granule cells }\end{array}$} \\
\hline & IMR-32 & NB-39 & \\
\hline (1) Xanthoangelol & 4.13 & 9.12 & 10.5 \\
\hline (2) Xanthoangelol F & 5.83 & 9.12 & 26.5 \\
\hline (3) 4-Hydroxyderricin & 1.97 & 4.48 & 24.4 \\
\hline (4) Isobavachalcone & 5.61 & 6.22 & $>100$ \\
\hline (5) Xanthoangelol H & 15.9 & 20.0 & $>100$ \\
\hline (6) Xanthoangelol I & 13.4 & 16.7 & 16.3 \\
\hline (7) Xanthohumol & 1.80 & 15.6 & 12.1 \\
\hline \multirow{2}{*}{$\begin{array}{l}\text { (8) 4-O-Methylxanthohumol } \\
\text { cisplatin }\end{array}$} & 4.35 & 9.71 & 12.9 \\
\hline & 64.0 & 8.95 & None data \\
\hline
\end{tabular}

Cells were treated with the indicated chalcones $\left(1 \times 10^{-4}-1 \times 10^{-6} \mathrm{M}\right)$ for $48 \mathrm{~h}$, and cell viability was analyzed by MTT assay.

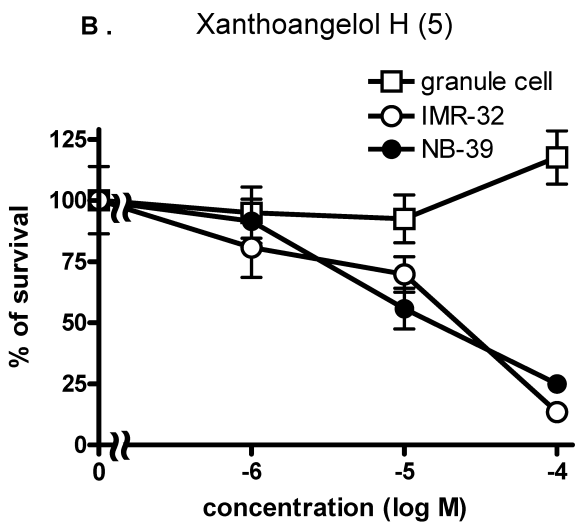

Fig. 2. Cytotoxic Effects of Isobavachalcone and Xanthoangelol H on Neuroblastoma (IMR-32 and NB-39) and Cerebellar Granule Cells as Shown by the MTT Assay

Cells were exposed to isobavachalcone (A) and xanthoangelol H (B) for $48 \mathrm{~h}$. Each plot shows the mean \pm S.E.M. survival rate relative to the control group. 
A.
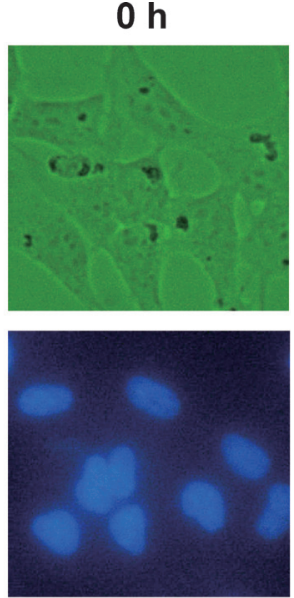

$4 \mathrm{~h}$
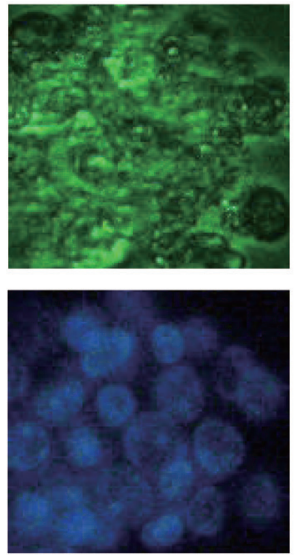

$8 \mathrm{~h}$
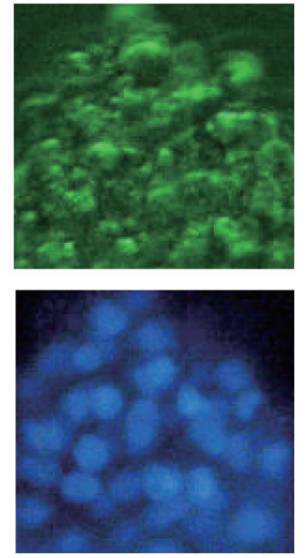

$24 \mathrm{~h}$
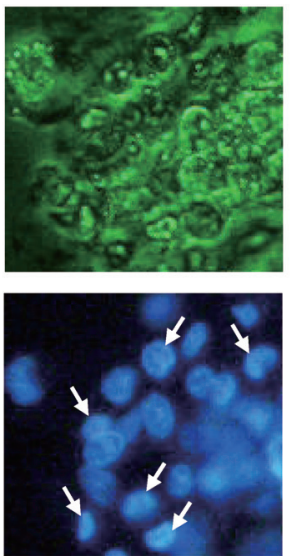

$48 \mathrm{~h}$
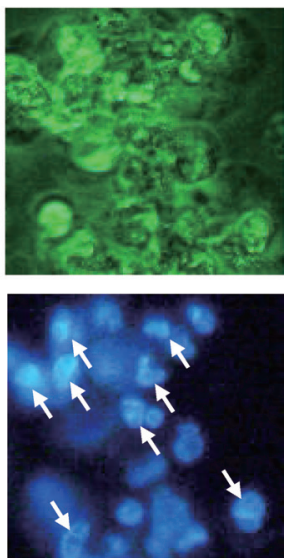

B.
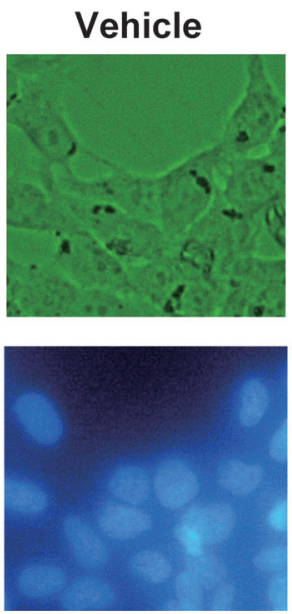

$10^{-6} \mathrm{M}$
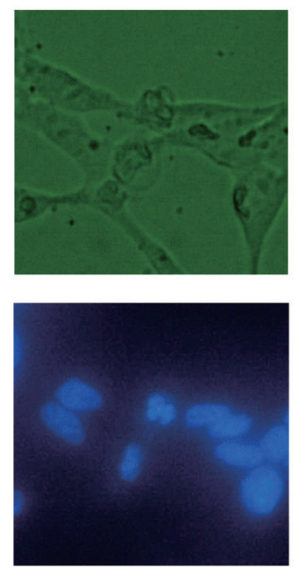

$10^{-5} \mathrm{M}$
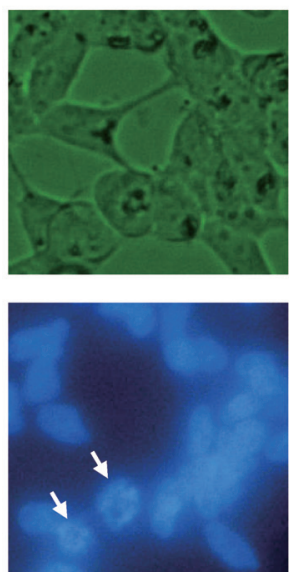

$10^{-4} \mathrm{M}$
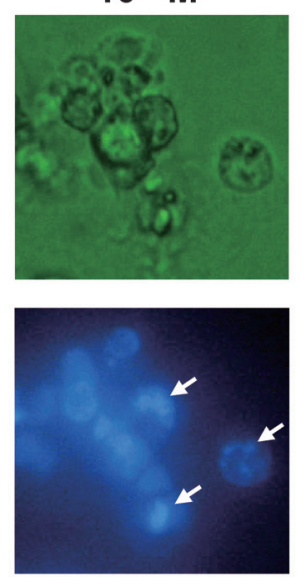

Fig. 3. Isobavachalcone-Induced Cell Shrinkage and Fragmentation Revealed by Nuclear Staining with Hoechst 33342 in IMR-32 Cells

(A) IMR-32 cells were exposed to isobavachalcone $\left(1 \times 10^{-4} \mathrm{M}\right)$ for $0-48 \mathrm{~h}$, then phase-contrast images (top) and fluorescent images (below) were taken. (B) IMR-32 cells were exposed to isobavachalcone $\left(1 \times 10^{-4}-1 \times 10^{-6} \mathrm{M}\right)$ for $24 \mathrm{~h}$, then phase-contrast images (top) and fluorescent images (below) were taken. Isobavachalcone induced nuclear shrinkage and fragmentation, as features of apoptotic cell death. White arrows indicate apoptotic cells.

creased at $48 \mathrm{~h}$ after application of isobavachalcone (4) in both cell lines, whereas cleaved caspase-3 $(17 \mathrm{kDa})$ was markedly increased at $24 \mathrm{~h}$ in IMR-32, and at $48 \mathrm{~h}$ in NB-39 (Fig. 4A). Pro-caspase-9 (47 kDa) was decreased by isobavachalcone $(4)\left(1 \times 10^{-4} \mathrm{M}\right)$ and cleaved caspase-9 $(35 \mathrm{kDa})$ was increased in a time-dependent manner in both the IMR-32 and NB-39 cell lines (Fig. 4B). Thus, these data revealed that isobavachalcone (4)-induced cell death involved activation of the apoptotic mitochondrial pathway.

Bcl-2 family proteins, consisting of pro-apoptotic (such as Bax, Bak, Bid, Bad) and anti-apoptotic (such as Bcl-2, Bcl$\mathrm{x}_{\mathrm{L}}, \mathrm{Bcl}-\mathrm{w}$ ) members, serve as critical regulators of the death signal. Bax and Bcl-2 are important regulators of cytochrome $\mathrm{c}$ release from mitochondria. As shown in Fig. $4 \mathrm{C}$, isobachalcone (4) $\left(1 \times 10^{-4} \mathrm{M}\right)$ markedly increased the level of Bax in both IMR-32 and NB-39 cell lines in a time-dependent manner. On the other hand, isobavachalcone (4) did not change the level of Bcl-2. Bcl-2 has been shown to form a heterodimer with $\mathrm{Bax}$, and the $\mathrm{Bax} / \mathrm{Bcl}-2$ ratio is an important key in determining whether cells will undergo apoptosis. ${ }^{4}$ Isobavachalcone (4) significantly increased this ratio in IMR32 and NB-39 cells. Thus it seems that isobavachalcone (4)induced apoptosis involves $\mathrm{Bax} / \mathrm{Bcl}-2$ signal transduction.

\section{DISCUSSION}

Our study showed that chalcones isolated from A. keiskei and $H$. lupulus induced cytotoxicity in human neuroblastoma cells. Especially, isobavachalcone (4), a constituent of $A$. keiskei, was revealed to exert an apoptosis-inducing effect against neuroblastoma cells, but not normal cells.

It has been reported that some chalcones derived from A. keiskei and $H$. lupulus have antitumor activity in vitro and in vivo. ${ }^{10,12,14-19)}$ Especially, xanthohumol (7), a well documented chalcone constituent of $H$. lupulus, induces apoptotic cell death in tumor cell lines (breast, colon cancer and leukemia) ${ }^{18-21)}$ and has both chemopreventive ${ }^{16)}$ and anti-angiogenesis effects. ${ }^{17)}$ Among the chalcones derived from $A$. keiskei, xanthoangelol (1) and 4-hydroxyderricin (3) possess antitumor and antimetastatic activity, ${ }^{14,15)}$ and isobavachalcone (4) inhibits tumor promotion in vivo. ${ }^{13)}$ Recently, we demonstrated that xanthoangelol (1) induced apoptotic cell death in neuroblastoma and leukemia cell lines. ${ }^{28}$ In this study, all of the chalcones we examined were shown to possess potent cytotoxicity against two neuroblastoma cells (IMR-32 and NB-39), and all the chalcones showed similar potency in this respect. This result suggests that many chal- 
IMR-32

A . Caspase-3

B. Caspase-9
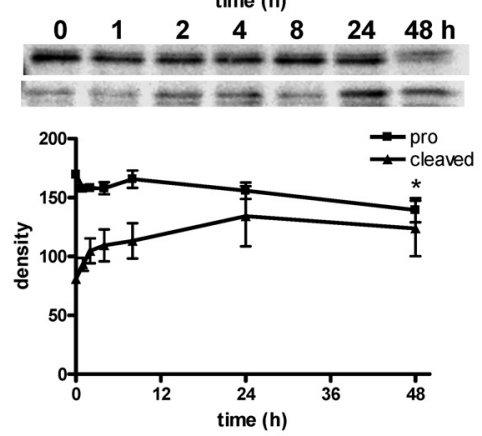

C . Bcl-2 and Bax

a.

b.
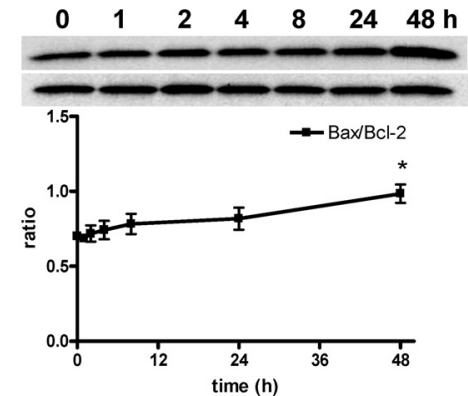

NB-39
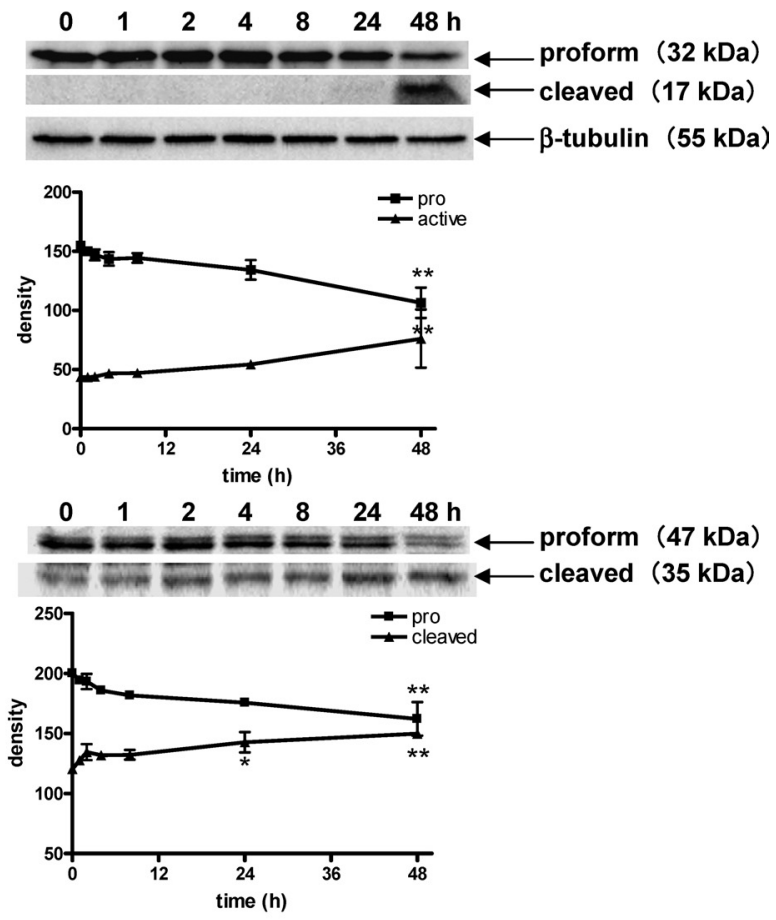

$\begin{array}{lllllll}0 & 1 & 2 & 4 & 8 & 24 & 48 \mathrm{~h}\end{array}$

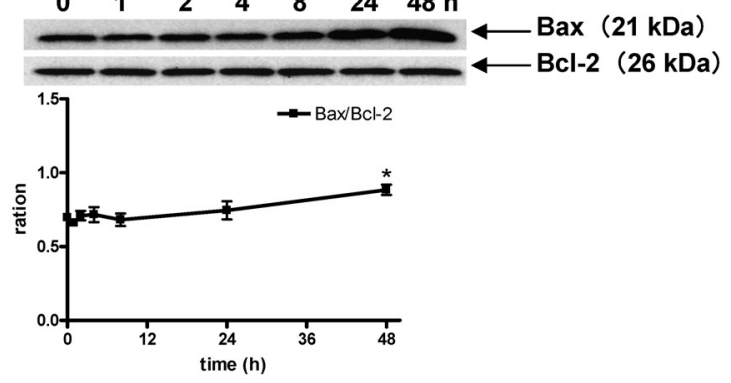

Fig. 4. Effects of Isobavachalcone on Caspase-3, Caspase-9, Bcl-2 and Bax Protein

Isobavachalcone $\left(1 \times 10^{-4} \mathrm{M}\right)$ was applied for $0-48 \mathrm{~h}$. Graphs on the left are for IMR-32, and those on the right are for NB-39. (A) Immunoblotting showed that pro-caspase-3 was slightly decreased at $48 \mathrm{~h}$ by isobavachalcone in both cell lines, while cleaved caspase- 3 was markedly increased at $24 \mathrm{~h}$ in IMR-32 and at $48 \mathrm{~h}$ in NB-39. The graphs below indicate the time course of the expression of both proteins. (B) Pro-caspase-9 and cleaved caspase-9 were detected by immunoblotting in neuroblastoma cell lines. Caspase-9 was cleaved and activated by isobavachalcone in both neuroblastoma cells. The graphs below indicate the time course of the expression of both proteins. These data suggest that the mitochondrial pathway plays an important role in the apoptosis induced by isobavachalcone. (C) (a) The pro-apoptotic protein Bax, but not the anti-apoptotic protein Bcl-2, both key molecules in the mitochondrial pathway, was significantly increased by isobavachalcone and (b) the Bax/Bcl-2 ratio was increased by isobavachalcone, as revealed by densitometry analysis using NIH image J software. All symbols and bars show the mean \pm S.E.M. $* p<0.05, * * p<0.01 v s$. 0 h control compared by one-way ANOVA followed by Bonferroni's test.

cones in $A$. keiskei and H. lupulus could be potentially useful anticancer agents, in addition to reported chalcones such as xanthoangelol (1) and xanthohumol (7). Moreover, as the synergistic anti-cancer effect of chalcones extracted from $A$. keiskei or $H$. lupulus may be considerable, therapeutic potential of crude extracts can also be expected.

In this study, isobavachalcone (4) and xanthoangelol $\mathrm{H} \mathrm{(5),}$ but not the other 6 chalcones $(\mathbf{1}-\mathbf{3}, \mathbf{6}-\mathbf{8})$, affected the cell viability of primary cultured rat cerebellar granule cells. Kimura et al. demonstrated the tumor selectivity of xanthoangelol (1) and 4-hydroxyderricin (3) in a DNA synthesis experiment using human umbilical vein endothelial cells (HUVEC). ${ }^{14,15)}$ In contrast, our results showed that both xanthoangelol (1) and 4-hydroxyderricin (3) induced cell death in cerebellar granule cells as well as neuroblastoma cells. Cerebellar granule cells are reported to be more sensitive than normal astrocytes to chemotherapeutic drugs. ${ }^{29)}$ In previous studies, normal human dermal fibroblasts (NHDF) and peripheral blood mononuclear cells (PBMC) have also been used as control normal cells to clarify tumor selectivity. ${ }^{30-32)}$ We also examined chalcone-induced cytotoxicity using NHDF cells, but all of the chalcones (1-8) showed cytotoxic effects against NHDF, as well as neuroblastoma cells, by MTT assay (data not shown). From these results, it seems difficult to explain the tumor selectivity solely by comparing a few types of normal cells in vitro. However, we demonstrated the selective cytotoxicity of isobavachalcone (4) and xanthoangelol $\mathrm{H} \mathrm{(5)}$ against neuroblastoma cell lines at least in comparison to normal neuronal cells.

Isobavachalcone (4), a constituent of $A$. keiskei, induced apoptotic cell death with caspase-3 and -9 activation and Bax upregulation in neuroblastoma cell lines. Generally, caspase- 8 deletion is often observed in neuroblastoma. Some neuroblastoma cell lines including IMR-32 do not express caspase- 8 protein. ${ }^{33)}$ In NB-39, caspase- 8 was slightly expressed, but the active form was not detected after perfusion 
with isobavachalcone (4) (data not shown). These data indicate that isobavachalcone (4) induces mitochondrial apoptosis. Bax induction seems to play an important role in isobavachalcone (4)-induced mitochondrial apoptosis. In contrast, we had previously shown that Bax did not contribute to the mechanism of xanthoangelol (1)-induced apoptosis. $^{28)}$ On the other hand, xanthohumol (7) induces apoptosis by down-regulation of Bcl-2 in colon cancer cells. ${ }^{20)}$ As shown in Fig. 1, the chemical structure of isobavachalcone (4) is similar to that of xanthoangelol (1) except for the geranyl side chain, and xanthohumol (7) is a compound in which a methoxy group is introduced into isobavachalcone (4). These findings imply that differences in the side chain are important for regulation of Bax/Bcl-2 activity and/or expression. Considering the fact that isobavachalcone (4), but not xanthoangelol (1) and xanthohumol (7), shows differences in cytotoxicity among neuroblastoma and cerebellar granule cells, the side chain structures may influence tumor selectivity. Moreover, the importance of the side chain to cell reactivity is supported by a previous report indicating that the side chain structure of chalcones derived from A. keiskei influences NF- $\kappa$ B suppression. ${ }^{10)}$

In conclusion, our results indicate that isobavachalcone induces apoptotic cell death via the mitochondrial pathway in neuroblastoma. Therefore it is suggested that isobavachalcone may be a potentially useful, safe and selective antitumor agent against neuroblastoma.

Acknowledgements We thank Dr. Toshimitsu Suzuki, Fukushima Medical University School of Medicine, for providing NB-39 cells. This work was supported by the "Academic Frontier" Project for Private Universities: matching fund subsidy from MEXT (Ministry of Education, Culture, Sports, Science and Technology) 2002-2006, and a Nihon University Research Grant for 2006.

\section{REFERENCES}

1) Nakagawara A., Ohira M., Cancer Lett., 204, 213 -224 (2004).

2) Torkin R., Lavoie J. F., Kaplan D. R., Yeger H., Mol. Cancer Ther., 4, $1-11(2005)$.

3) Tonini G. P., Pistoia V., Curr. Pharm. Des., 12, 2303-2317 (2006).

4) McGill G., Fisher D. E., Front. Biosci., 15, d353-d379 (1997).

5) Hengartner M. O., Nature (London), 407, 770_776 (2000).

6) Oue T., Fukuzawa M., Kusafuka T., Kohmoto Y., Imura K., Nagahara S., Okada A., J. Ped. Surg., 31, 251-257 (1996).

7) Johnstone R. W., Ruefli A. A., Lowe S. W., Cell, 108, 153-164 (2002).
8) Ogawa H., Nakashima S., Baba K., Clin. Exp. Pharmacol. Physiol., 30, 284-288 (2003).

9) Matsuura M., Kimura Y., Nakata K., Baba K., Okuda H., Planta Med., 67, 230-235 (2001).

10) Sugii M., Ohkita M., Taniguchi M., Baba K., Kawai Y., Tahara C., Takaoka M., Matsumura Y., Biol. Pharm. Bull., 28, 607-610 (2005).

11) Akihisa T., Tokuda H., Ukiya M., Iizuka M., Schneider S., Ogasawara K., Mukainaka T., Iwatsuki K., Suzuki T., Nishino H., Cancer Lett., 201, 133-137 (2003).

12) Okuyama T., Takata M., Takayasu J., Hasegawa T., Tokuda H., Nishino H., Iwashima A., Planta Med., 57, 242-246 (1991).

13) Akihisa T., Tokuda H., Hasegawa D., Ukiya M., Kimura Y., Enjo F., Suzuki T., Nishino H., J. Nat. Prod., 69, 38-42 (2006).

14) Kimura Y., Taniguchi M., Baba K., Planta Med., 70, 211-219 (2004).

15) Kimura Y., Baba K., Int. J. Cancer, 106, 429-437 (2003).

16) Gerhauser C., Alt A., Heiss E., Gamal-Eldeen A., Klimo K., Knauft J., Neumann I., Scherf H. R., Frank N., Bartsch H., Becker H., Mol. Cancer Ther., 1, 959-969 (2002).

17) Adriana A., Dell'Eva R., Vene R., Ferrari N., Buhler D. R., Noonan D. M., Fassina G., FASEB J., 20, 527-529 (2006).

18) Miranda C. L., Stevens J. F., Helmrich A., Henderson M. C., Rodriguez R. J., Yang Y. H., Deinzer M. L., Barnes D. W., Buhler D. R., Food Chem. Toxicol., 37, 271-285 (1999).

19) Vanhoecke B., Derycke L., Van Marck V., Depypere H., De Keukeleire D., Bracke M., Int. J. Cancer, 117, 889-895 (2005).

20) Pan L., Becker H., Gerhäuser C., Mol. Nutr. Food Res., 49, 837-843 (2005).

21) Lust S., Vanhoecke B., Janssens A., Philippe J., Bracke M., Offner F., Mol. Nutr. Food Res., 49, 844-850 (2005).

22) Ito Y., Ishige K., Zaitsu E., Anzai K., Fukuda H., J. Neurochem., 65, $75-83$ (1995).

23) Kosuge Y., Koen Y., Ishige K., Minami K., Urasawa H., Saito H., Ito Y., Neuroscience, 122, 885-895 (2003).

24) Liu Y., Peterson D. A., Kimure H., Schubert D., J. Neurochem., 69, 581-593 (1997)

25) Ishige K., Chen Q., Sagara Y., Schubert D., J. Neurosci., 21, 6069 6076 (2001).

26) Arakawa M., Ushimaru N., Osada N., Oda T., Ishige K., Ito Y., Neurosci. Res., 55, 255-263 (2006).

27) Bradford M. M., Anal. Biochem., 72, 248-254 (1976).

28) Tabata K., Motani K., Takayanagi N., Nishimura R., Asami S., Kimura Y., Ukiya M., Hasegawa D., Akihisa T., Suzuki T., Biol. Pharm. Bull., 28, 1404-1407 (2005).

29) Wick A., Wick W., Hirrlinger J., Gerhardt E., Dringen R., Dichgans J., Weller M., Schulz J. B., J. Neurochem., 91, 1067-1074 (2004).

30) Postiglione L., Di Domenico G., Caraglia M., Marra M., Giuberti G., Del Vecchio L., Montagnani S., Macri M., Bruno E. M., Abbruzzese A., Rossi G., Int. J. Oncol., 26, 1193-1201 (2005).

31) Yanamoto S., Iwamoto T., Kawasaki G., Yoshitomi I., Baba N., Mizuno A., Cancer Lett., 223, 67-76 (2005).

32) Rocha D. D., Militao G. C., Veras M. L., Pessoa O. D., Silveira E. R., Alves A. P., de Moraes M. O., Pessoa C., Costa-Lotufo L. V., Life Sci., 79, 1692-1701 (2006).

33) Hopkins-Donaldson S., Yan P., Bourloud K. B., Muhlethaler A., Bodmer J. L., Gross N., Oncogene, 21, 6132-6137 (2002). 